\title{
Keanekaragaman Jenis Belalang (Ordo Orthoptera) Di Pertanian Kacang Hijau (Vigna radiata L.) Desa Manusak Kabupaten Kupang
}

\author{
Chatarina Gradict Semiun ${ }^{1}$, Yulita Iryani Mamulak ${ }^{2}$ \\ ${ }^{1,2}$ Program Studi Biologi Fakultas Matematika dan Ilmu Pengetauan Alam \\ Universitas Katolik Widya Mandira, Jl. Jend. A. Yani No 50-52 Kupang, NTT

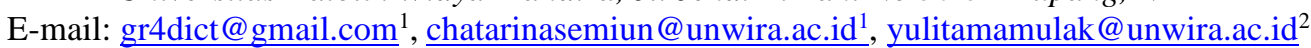

\begin{abstract}
Abstrak
Keberadaan belalang menentukan kualitas suatu lahan pertanian.Belalang memiliki peranan sebagai herbivora, predator, dekomposer, dan hama sehingga berpotensi dijadikan sebagai indikator kualitas lahan pertanian.Belalang sering dianggap sebagai serangga pengganggu, padahal memiliki peranan yang vital di ekosistem.Penelitian ini bertujuan untuk menentukan keanekaragaman jenis belalang di pertanian kacang hijau di desa Manusak.Penelitian ini bersifat deskriptif kuantitatif.Pengambilan sampel belalang dengan menggunakan jebakan pitfall trap, hand sorting dan jaring serangga.Pengukuran faktor lingkungan dilakukan dengan mengambil data Global Positioning System (GPS), suhu tanah, kelembaban tanah, pH tanah, berat jenis tanah dan water holding capacity. Secara keseluruhan didapatkan tujuhjenis belalang, dari tigafamili dengan total individu berjumlah 30. Ketiga famili tersebut meliputi Pyrgomorphidae, Tettigoniidae, dan Acrididae.Nilai H' adalah 1,882 tergolong sedang.Nilai R1 adalah 1,764 tergolong rendah.
\end{abstract}

Kata Kunci: Keanekaragaman belalang, Ordo Orthoptera, Kacang hijau

\section{PENDAHULUAN}

Belalang adalah jenis serangga ordo orthoptera dengan jumlah jenis mencapai 20.000 (Prakoso, 2017). Sebagian anggota orthoptera dikenal sebagai pemakan tumbuhan, namun ada beberapa di antaranya yang bertindak sebagai dekomposer, dan predator pada serangga lain. Belalang tergolong herbivora, terkadang menjadi hama pada tanaman serealia dan sayuran.

Belalang berkumpul dalam jumlah jutaan di suatu lokus pertanian sehingga dapat menyebabkan kerusakan tanaman dalam skala yang besar (More and Nikam, 2016).Keanekaragaman belalang memiliki potensi yang kuat sebagai indikator kualitas suatu lahan. Penelitian yang dilakukan oleh Bazelet and Samways (2011) menemukan 11 dari 24 jenis belalang sangat efektif sebagai indikator karateristik suatu ekosistem.

Pertumbuhan dan perkembangan balalang dipengaruhi oleh faktor abiotik dan biotik. Faktor abiotik meliputi suhu, pH, kelembaban, curah hujan,dan intensitas cahaya. Sedangkan faktor biotik meliputi semua makhluk hidup yang terdapat di habitat belalang.Belalang dapat ditemukan di hampir semua ekosistem
terrestrial.Salah satunya ekosistem pertanian kacang hijau.Kacang hijau merupakan salah satu jenis komoditas pertanian yang banyak dibudidayakan di kabupaten Kupang, provinsi Nusa Tenggara Timur.Menurut data BPS provinsi NTT (2017), produksi kacang hijau di kabupaten kupang mencapai 57 ton.Tujuan dari penelitian ini adalah untuk menentukan keanekaragaman jenis belalang di lahan pertanian kacang hijau desa Manusak yang terletak di kecamatan Kupang Timur.

\section{METODE PENELITIAN}

Penelitian ini dilaksanakan pada bulan Maret sampai dengan Juli 2019 di lahan pertanian kacang hijau desa Manusak, kecamatan Kupang Timur, kabupaten Kupang. Bahan yang digunakan adalah jenis-jenis belalang yang tertangkap, aquades, detergen dan alkohol $70 \%$. Alat yang digunakan meliputi soil tester 4 in 1, thermometer digital, roll meter, botol jam, kamera dan alat tulis menulis.

Penelitian ini bersifat deskriptif kuantitatif dengan eksplorasi.Di lahan pertanian kacang hijau dibuat 5 petak berukuran $5 \mathrm{~m}$ x $5 \mathrm{~m}$, dengan jarak antar 
petak 5 meter.dalam petak dipasangkan jebakan pitfall trap secara diagonal, kemudian dibiarkan selama 24 jam. Selanjutnya untuk menghindari masuknya air hujan pada jebakandiberi naungan.Selain itu, pengambilan sampel belalang juga dilakukan dengan tangan (hand sorting) dan jaring serangga. Koleksi sampel pada pitfall trap dibiarkan selama 24 jam. Kemudian dilakukan identifikasi menggunakan buku identifikasi, dan browsing internet pada website terkait sepertibugguide.net dan animaldiversity.org.Pengukuran faktor lingkungan dilakukan dengan mengambil data koordinat, elevasi, suhu tanah, suhu udara, kelembaban tanah, $\mathrm{pH}$, berat jenis tanah dan water holding capacity.

Keanekaragaman jenis belalang dihitung berdasarkan Semiun dan Stanis (2016) yaitu indeks keanekaragaman Shanon-Wiener dan indeks kekayaan jenis.Selanjutnya keanekaragaman belalang dikaitkan dengan variabel abiotikdianalisis dengan multivariate clutser menggunakan software PAST.

\section{HASIL DAN PEMBAHASAN}

Di lahan pertanian kacang hijaudesa Manusak ditemukan tujuhjenis belalang, daritiga famili dengan total individu berjumlah 30. Ketiga famili tersebut meliputi Pyrgomorphidae, Tettigoniidae, dan Acrididae (Tabel 1).

Tabel 1. Jenis belalang di lahan pertanian kacang hijau

\begin{tabular}{|c|c|c|c|}
\hline No & Famili & Jenis & Jumlah \\
\hline 1 & \multirow{3}{*}{ Pyrgomorphidae } & Atractomorpha crenulata & 6 \\
\hline 2 & & Atractomorpha sinensis & 5 \\
\hline 3 & & Atractomorpha sp. & 6 \\
\hline 4 & Tettigoniidae & Scudderia sp. & 2 \\
\hline 5 & \multirow{4}{*}{ Acrididae } & Dissosteira Carolina & 3 \\
\hline 6 & & Xenocatantops humilis & 5 \\
\hline 7 & & Locusta migratoria & 3 \\
\hline & & TOTAL & 30 \\
\hline
\end{tabular}

Berdasarkan Tabel 1. Family Pyrgomorphidae adalah jenis belalang yang paling banyak ditemukan. Penelitian ini ditemukan tiga jenis yaitu Atractomorpha crenulata, Atractomorpha sinensis, dan Atractomorpha sp. Pyrogomorphidae hidup pada daerah tropis dan subtropis.Pyrgomorphidae merupakan salah satu famili dari superfamili Acridoidea. Pyrgomorphidae hanya memiliki satu subfamili Pyrgomorphinae yang terdiri dari 29 genus, dan sekitar 400 jenis telah diidentifikasi (Seino and Njoya, 2018).

Belalang dari famili Acrididae ditemukan terbanyak kedua setelah Pyrgomorphidae. Dalam penelitian ini ditemukan tiga jenis yaitu Dissosteira carolina, Xenocatantops humilis, dan Locusta migratoria. Acrididae tergolong belalang dengan antenna pendek dan berperan sebagai herbivora pada ekosistem
(Sugiarto, 2018). Famili Acrididae sering menimbulkan permasalahan di ekosistem pertanian ketika berperan sebagai hama. Kumar and Usmani (2014) menyatakan bahwa belalang tersebar luas di semua sistem ekologi dengan kepentingan ekonomi yang signifikan karena perannya yang merusak bagi hampir semua jenis vegetasi hijau.Di lahan pertanian kacang hijau potensi sebagai hama dari jenis belalang ini tidak nampak karena jumlahnya yang sedikit. Selanjutnya, ditemukan jenis belalang dari famili Tettigoniidae yaitu Scudderia sp. Tettigoniidae dapat berperan sebagai musuh alami bagi hama tanaman (Falahudin dkk., 2015). Penelitian Sugiarto (2018) menemukan famili Tettigoniidae dan Pyrgomorphidae paling banyak berada di daerah pesawahan.

Gambar 1 menunjukkan bahwa keanekaragaman jenis belalang di lahan 
pertanian kacang hijau tertinggi dimiliki oleh Atractomorpha crenulata dan Atractomorpha sp.Sedangkan terendah dimiliki oleh Scuderria sp. Tingkat keanekaragaman jenis belalang yang bervariasi dipengaruhi oleh kelimpahan jenisnya.

Rerata indeks keanekaragaman di lahan pertanian kacang hijau adalah 1,882/tergolong sedang (Tabel 2).Terdapat beberapa kategori tingkat keanekaragaman, yaitu jika H' lebih kecil dari 1,00 maka keanekaragaman tergolong rendah, sedangkan jika H' adalah 1,00- 3,00 maka keanekaragaman sedang, dan jika H' lebih besar atau sama dengan 4,00 maka keanekaragaman tergolong tinggi (Pradhana dkk., 2014).

Tingkat keanekaragaman dipengaruhi oleh berbagai faktor salah satunya keberadaan jenis dan jumlah tumbuhan. Di lokasi pengamatan, dominan adalah tanaman kacang hijau, namun ditemukan pula jenis tumbuhan lain seperti padi, terung, gamal, asam, pisang, dan lontar.Variasi jenis tumbuhan diduga menyebabkan adanya variasi jenis belalang yang ditemukan.

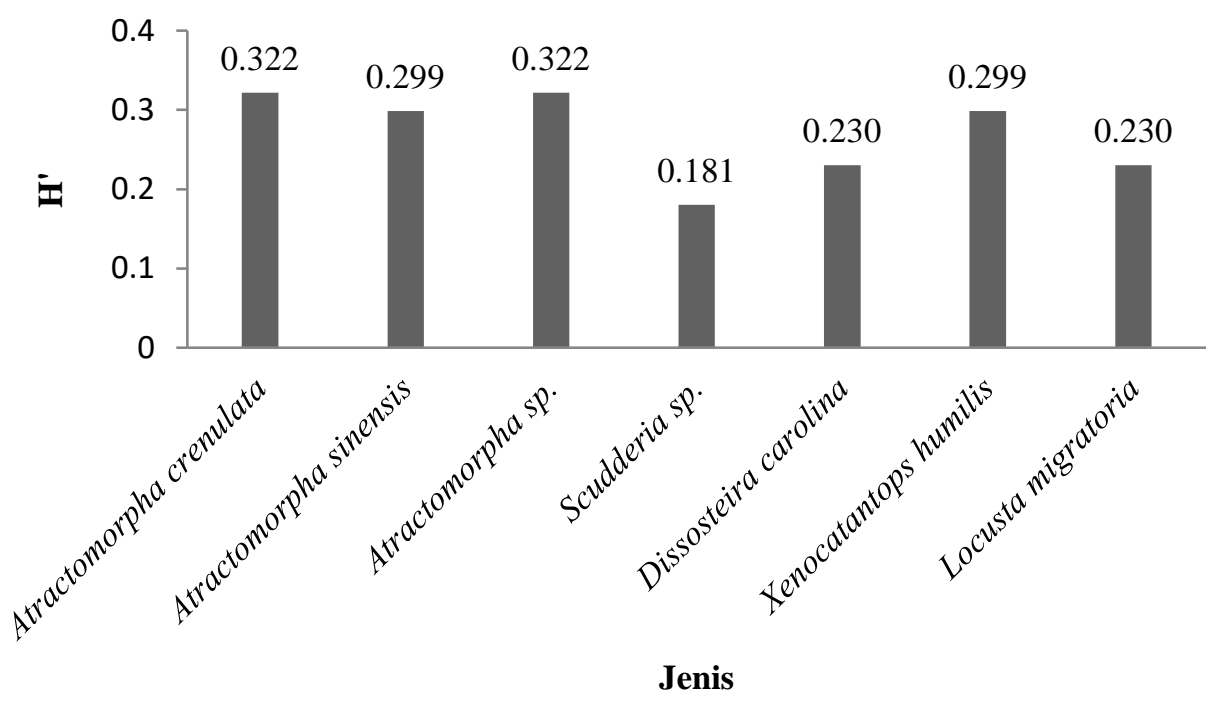

Gambar 1. Hasil analisis Kenaekaragaman jenis Shannon-Wiener (H') belalang di lahan pertanian kacang hijau desa Manusak

Indeks kekayaan jenis (R1) yang ditemukan di lahan pertanian kacang hijau adalah 1,764 tergolong rendah (Tabel 2).Berdasarkan Magurran (1988), nilai R1 lebih kecil dari 3,5 menunjukkan kekayaan jenis yang tergolong rendah, nilai R1 3,5 sampai dengan 5,0 menunjukkan kekayaan jenis tergolong sedang, sedangkan nilai R1 lebih dari 5,0 menunjukkan kekayaan jenis yang tergolong tinggi.

Rendahnya nilai kekayaan jenis disebabkan adanya beberapa jenis belalang yang dominan khususnya genus Atractomorpha. Ismaini dkk., (2015) menegaskan bahwa indeks kekayaan membagi jumlah jenis dengan fungsi logaritma natural yang mengindikasikan bahwa pertambahan jumlah jenis berbanding terbalik dengan pertambahan jumlah individu. Hal ini juga menunjukan bahwa biasanya pada suatu komunitas/ekosistem yang memiliki banyak jenisakan memiliki sedikit jumlah individu pada setiap jenis tersebut. 
Tabel 2.Keanekaragaman Belalang di Pertanian kacang

Hijau Desa Manusak

\begin{tabular}{cccc}
\hline No & Keanekaragaman & Nilai & Kategori \\
\hline \multirow{2}{*}{1} & $\begin{array}{c}\text { Indeks keanekaragaman Shannon- } \\
\text { Wiener (H') }\end{array}$ & 1,882 & Sedang \\
\hline 2 & Indeks Kekayan Jenis (R1) & 1,764 & Rendah \\
\hline
\end{tabular}

Berdasarkan hasil analisis clutser menunjukkan bahwa dari tujuhjenis belalang yang ditemukan di lahan partanian kacang hijau dibentuk tiga kelompok berdasarkan kedekatan karakteristik variabel keanekaragaman belalang dan variable abiotik. Urutan kemiripan di antara tujuh jenis belalang tersebut digambarkan pengelompokannya dengan dendogram yang diperlihatkan pada Gambar 2.

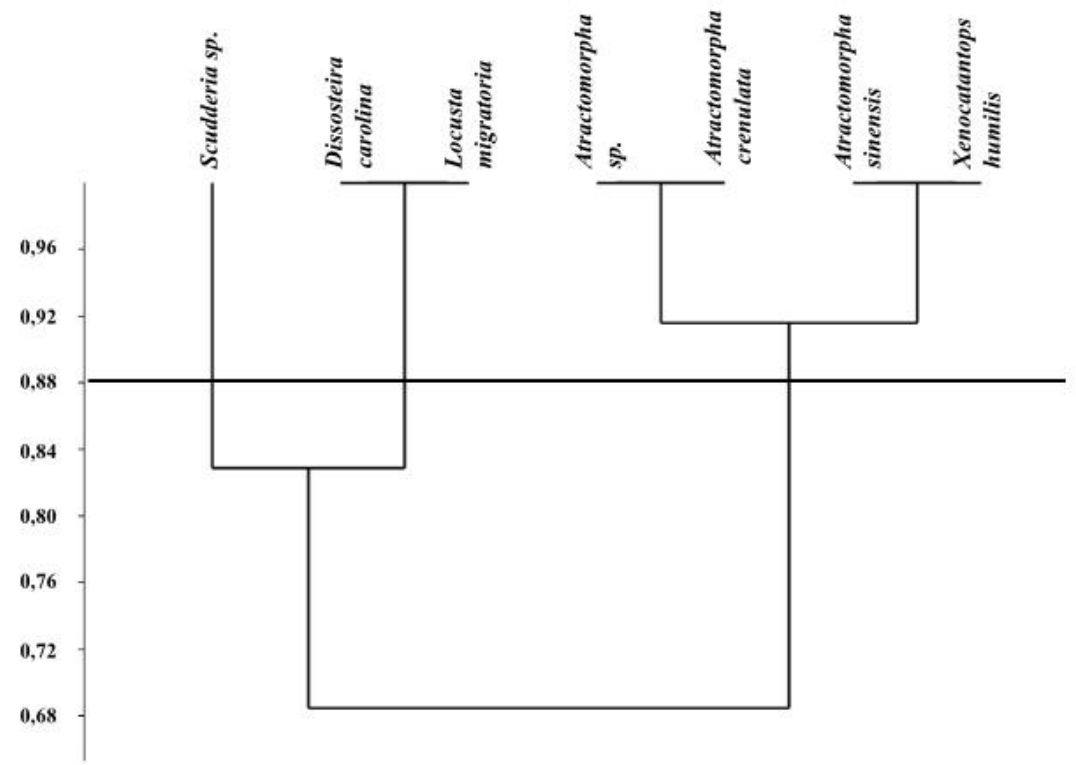

Gambar 2. Hasil analisis clutser menggunakan kesamaan Bray-Curtis variabel keanekaragaman belalang (H', R1, Jumlah Individu, KR) dan variabel abiotik (Suhu tanah, pH, WHC, Berat jenis tanah, elevasi).

\section{KESIMPULAN}

Berdasarkan penelitian yang telah dilakukan di lahan pertanian kacang hijau desa Manusak, kecamatan Kupang Timur, Kabupaten Kupang ditemukan tujuh jenis belalang dari tiga famili.Ketiga family tersebut adalah Pyrgomorphidae, Tettigoniidae, dan Acrididae.

Rerata indeks keanekaragaman di lahan pertanian kacang hijau tergolong sedang (1.882), dan kekayaan jenis tergolong rendah (1.764).Atractomorpha crenulata dan Atractomorpha sp.
Menunjukkan keanekaragam jenis tertinggi, sedangkan terendah dimiliki oleh Scuderria $s p$.

\section{UCAPAN TERIMA KASIH}

Terima kasih kepada DIKTI yang telah memberikan sumbangan dana hibah penelitian dosen pemula periode tahun 2019. Kepada para mahasiswa yang telah terlibat dalam mensukseskan penelitian ini. 
DAFTAR PUSTAKA

Badan Pusat Statistik Provinsi NTT. 2017. Produksi Kacang Hijau (Ton) Menurut Kabupaten/Kota di Provinsi Nusa Tenggara Timur, 2017.https://ntt.bps.go.id (diakses Juli 2019).

Bazelet, C. S., Samways M. J. 2011.Identifying grasshopper bioindicators for habitat quality assessment of ecological networks.Ecological Indikator, 11 (5) : 1259-1269

Falahudin, I., Mareta D. E., Rahayu I. A. P. 2015.Diversitas Serangga Ordo Orthoptera Pada Lahan Gambut Di Kecamatan Lalan Kabupaten Musi Banyuasin.Bioilmi, 1(1) : 1-7.

Ismaini, L, Masfiro L., Rustandi, Sunandar S. 2015. Analisis komposisi dan keanekaragaman tumbuhan di Gunung Dempo, Sumatera Selatan.Prossiding Seminar Nasional Masyarakat Biodiversitas Indonesia, 1(6): 13971402. ISSN: $2407-8050$

Kumar, H, Usmani M. K. 2014. Taxonomic studies on Acrididae (Orthoptera: Acridoidea) from Rajasthan (India). Journal of Entomology and Zoology Studies, 2 (3): 131-146.

Magurran, A. E. 1988. Ecological Diversity and its Measurement.Croom Helm ltd. London.

More, S. V., \& Nikam K .N. 2016. Studies Grasshoppers (Orthoptera) in Tilari
Forest, Chandgad, Kolhapur District of Maharashtra (India). International Journal of Recent ScientificResearch (IJRSR), 7 (3) : 9457-9460.

Prakoso, B. 2017. Biodiversitas Belalang (Acrididae: Ordo Orthoptera) pada Agroekosistem (Zea mays 1.) dan Ekosistem Hutan Tanaman di Kebun Raya Baturaden, Banyumas. Biosfera, 34 ( 2): 80-88.

Seino, R. A., \&Njoya, M. T. M. 2018.Species Diversity of Pyrgomorphidae (Orthoptera: Caelifera) Grasshoppers in the North West Region of Cameroon. International Journal of Zoology and Applied Biosciences, 3 (1) : 104-109.

Semiun, C. G., Stanis S. 2016. Kelimpahan dan Keanekaragaman Arthropoda Tanah pada Lahan Pertanian Monokultur dan Polikultur Di Desa Labat Kupang. Bio Wallacea, 2 (3): 154-161.

Sugiarto, A. 2018. Inventarisasi Belalang (Orthoptera: Acrididae) Di Perkebunan Dan Persawahan Desa Serdang Menang, Kecamatan Sirah Pulau Padang, Kabupaten Ogan Komering Ilir. Kumpulan Artikel Insect Village, 1(1): 7-10.

Pradhana, R. A. I., Mudjiono G., Karindah S. 2014.Keanekaragaman Serangga dan Laba-Laba pada Pertanaman Padi Organik dan Konvensional.HPT, 2 (2) : 58-66. 